\title{
Analysis of Annual Energy Consumption of Apartment House with PCM Floor Heating System by Simulation
}

\author{
TaeWon Kim¹, Minyoung Kim¹, Jin Chul Park ${ }^{2}$ \\ ${ }^{1}$ Department of Architectural Engineering, Graduate School Chung-Ang University \\ Seoul 156-756, Republic of Korea \\ xngilsh@cau.ac.kr; kmyhg@naver.com \\ ${ }^{2}$ School of Architecture \& Building Science, Chung-Ang University \\ Seoul 156-756, Republic of Korea \\ jincpark@cau.ac.kr
}

\begin{abstract}
This study proposes a floor heating system using PCM for the conventional floor heating system to reduce the heating energy consumption in apartment buildings in Korea and explained the structure and characteristics of the system. Through the computer simulation program EnergyPlus ver.8.7.0. the PCM floor heating system analyzed indoor and floor surface temperatures for one year. The heating energy consumed in the existing apartment house was about $165,563.1 \mathrm{kWh}$, and the building applied to the PCM floor heating system used about $161,549.7 \mathrm{kWh}$ Therefore, it is expected that the PCM floor heating system can be utilized as a way to reduce the heating energy consumption of the apartment.
\end{abstract}

Keywords: Apartment House, Pase Change Material, PCM, EnergyPlus, Floor Heating, Energy Saving.

\section{Introduction}

The proportion of apartments in residential buildings in Korea is more than $65 \%$, and its share is steadily increasing. Most of these apartments have a concrete-based wet process and a floor heating system that uses hot water as a heat source. However, since the present system has only a sensible heat storage / discharge section, the thermal performance is very low. In order to keep indoor air and floor surface temperature comfortable, it is necessary to supply a large amount of hot water, It has disadvantages.

Therefore in this study, we propose a PCM (Phase Change Material) floor heating system, which is a floor heating system with only a sensible heating section in apartment house, and a PCM. The results of this study are as follows.

\section{Composition of PCM Floor Heating System}

The structure of the floor heating system, which is adopted by most apartment buildings in Korea, is constructed with the structure shown in Fig 1. However, in these structures, lightweight foam concrete and finishing mortar are the materials responsible for the heat storage, but these materials have very low heat storage capacity and when the hot water supply is interrupted, the surface temperature of the bottom rapidly decreases. Therefore, in order to maintain a comfortable floor surface temperature while satisfying the indoor heating set temperature, it is necessary to continuously supply hot water. As a result, energy consumption also increases.

In order to overcome these drawbacks, this study proposed a floor heating system with improved heat storage performance by inserting PCM $(10 \mathrm{~mm})$ instead of lightweight foam concrete and ending with mortar as in Fig 2 . Because of the superb heat storage performance of PCM, this system can keep the bottom surface temperature comfortable condition while intermittently supply hot water and energy. It is also easy to construct because it is similar to existing floor system. 


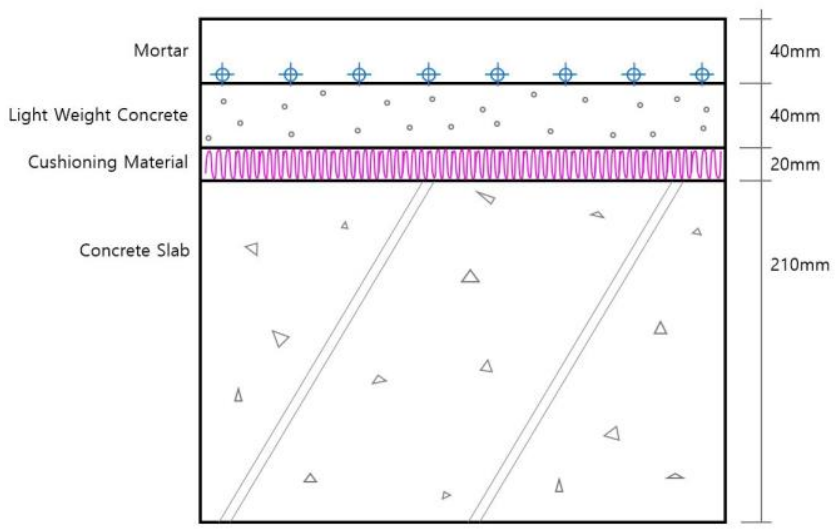

Fig. 1: The structure of existing floor heating system

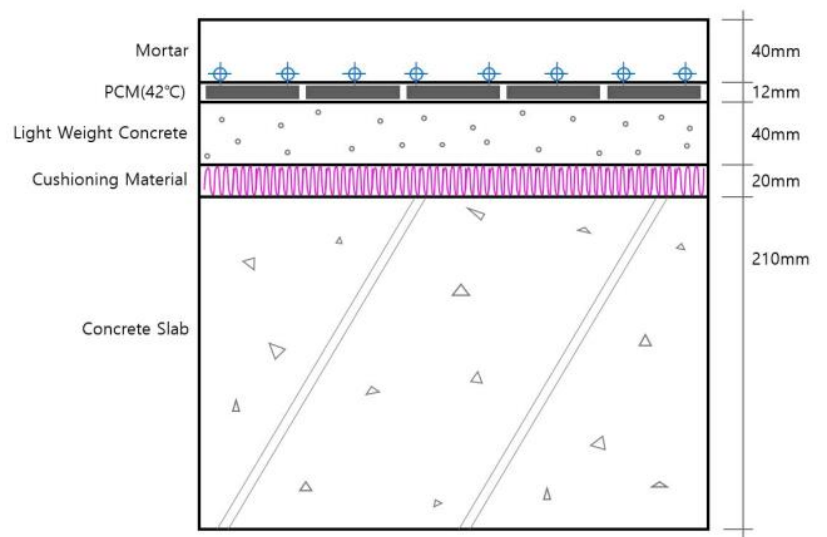

Fig. 2: The structure of PCM floor heating system.

\section{Performance Analysis of Heating Energy Reduction}

When the PCM floor heating system with proven heat storage performance is applied to a real apartment house, the energy saving performance is compared with the existing system.

In this study, a simulated apartment house receiving a heat source by district heating is modeled using computer simulation and set to the same condition based on weather data. We compared and analyzed the amount of heating energy used for one year in existing and PCM embedded apartment houses. The computer simulation program used is an EnergyPlus ver.8.7.0 (2016a) that can comprehensively analyze the environmental performance of buildings.

\subsection{Simulation}

The building overview for simulation is shown in fig3. The building was located in Seoul, southern and apartment house size of $10,290 \mathrm{~mm} \times 10,530 \mathrm{~mm} \times 2,800 \mathrm{~mm}$, with the ground floor being the lowest floor, third floor being the top floor and second floor being the base layer. Windows and doors of the outer skin were set as being installed only in the south. The data collection interval is every hour, with data from January 1 to December 31. 

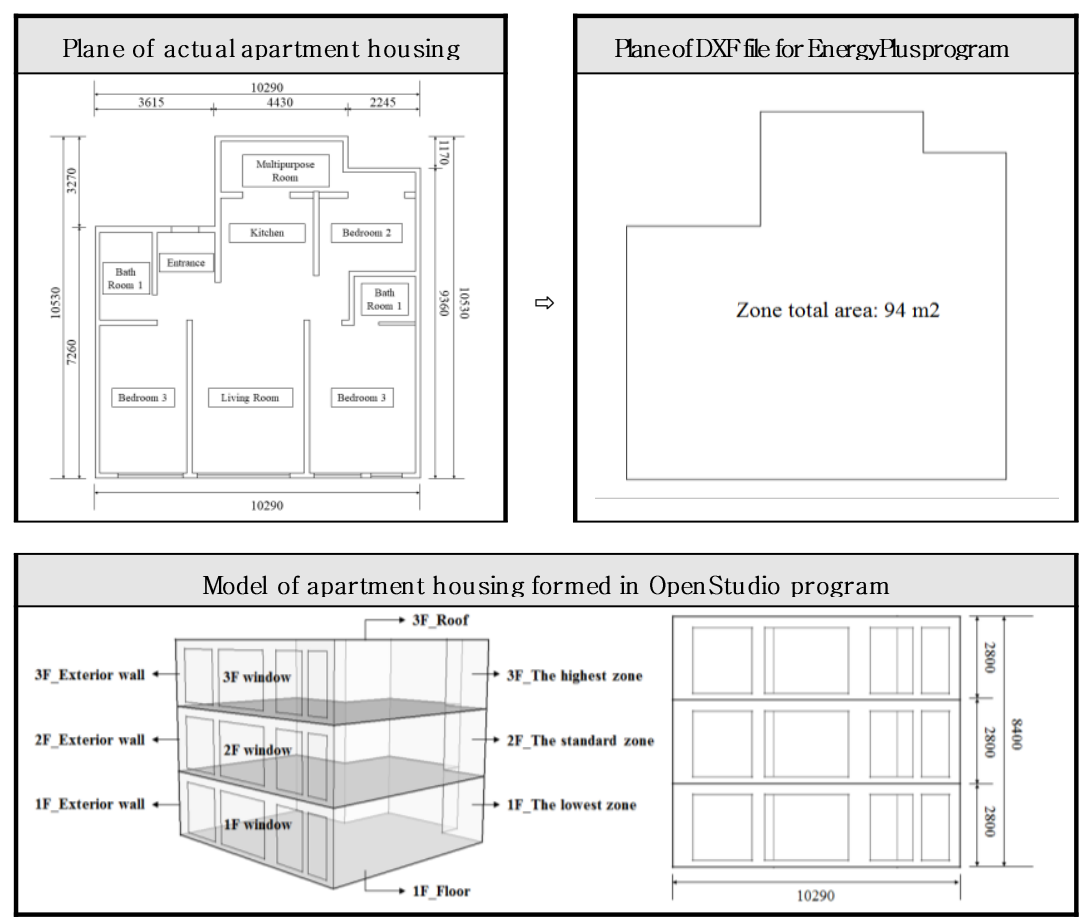

Fig. 3: Modeling overview of apartment house using simulation.

The heating conditions are as shown in Table 1 At night time (18:00 to 08:00) continuous heating, room temperature $22^{\circ} \mathrm{C}$, floor temperature were kept at $30^{\circ} \mathrm{C}$. During the weekday time zone (08:00 to 18:00), intermittent heating, room temperature $10^{\circ} \mathrm{C}$, and bottom surface temperature $15^{\circ} \mathrm{C}$ were maintained.

Also, The numerical value of the applied thermal energy (enthalpy) storage capacity of PCM $44^{\circ} \mathrm{C}$ was converted into Joule unit. The thickness of the PCM was analyzed based on $10 \mathrm{~mm}$, and how the surface temperature and energy consumption of the floor were varied.

Table 1: Indoor and floor surface setting temperature by time zone.

\begin{tabular}{|c|c|c|c|}
\hline Input type & Time & Control type & Input value \\
\hline \multirow{4}{*}{$\begin{array}{c}\text { Thermostat } \\
\text { Setpoint }\end{array}$} & $0: 00 \sim 08: 00$ & Indoor temperature & $22^{\circ} \mathrm{C}$ \\
\cline { 2 - 4 } & $08: 00 \sim 18: 00$ & Floor surface temperature & $30^{\circ} \mathrm{C}$ \\
\cline { 2 - 4 } & & Indoor temperature & $10^{\circ} \mathrm{C}$ \\
\cline { 2 - 4 } & \multirow{2}{*}{$18: 00 \sim 24: 00$} & Floor surface temperature & $15^{\circ} \mathrm{C}$ \\
\cline { 3 - 4 } & & Floor surface temperature & $22^{\circ} \mathrm{C}$ \\
\hline
\end{tabular}

\subsection{Result}

The results of the data collected on the floor surface temperature and the indoor air temperature of the reference floor at 1-hour intervals in the PCM $(10 \mathrm{~mm})$ apartment house are as follows. 


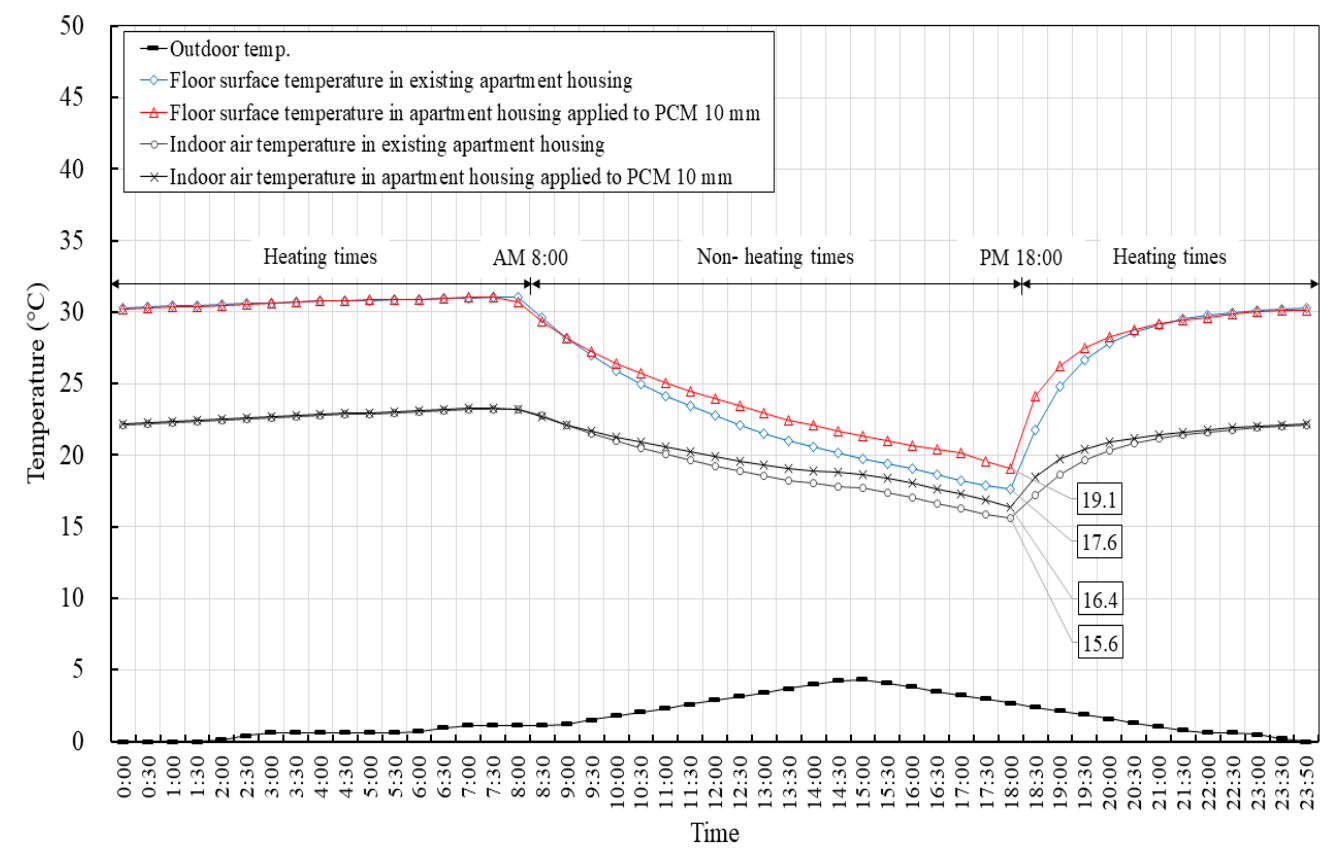

Fig. 4: Distribution of base floor temperature in apartment house floor heating with PCM (10mm).

After the heating has restarted, The surface heating temperature of the existing floor heating system at 18:00 was $17.6^{\circ} \mathrm{C}$ and the surface temperature of PCM was $19.1{ }^{\circ} \mathrm{C} .18: 00 \sim 08: 00$ during the heating operation, the floor surface temperature is about $30^{\circ} \mathrm{C}$, indoor air temperature is about $22^{\circ} \mathrm{C}$. Both conventional and PCM floor heating showed similar temperature distributions.

Especially, the annual energy saving rate of apartment house (base floor) hot water of conventional and PCM applied floor heating system during the heating period is $165,563.1 \mathrm{kWh}$ and the floor heating of PCM applied is $161,549.7 \mathrm{kWh}$ as shown in Fig5. It was revealed that there is a reduction of about $2.4 \%$.

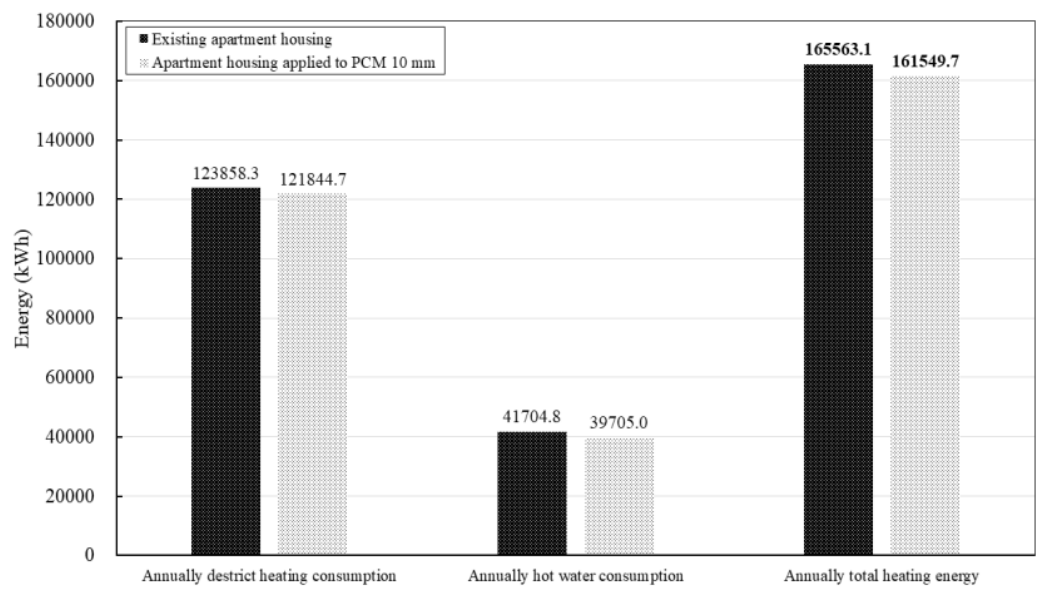

Fig. 5 : Reduction in annual heating energy consumption of apartment house floor heating with PCM (10mm).

\section{Conclusion}

This study proposes a PCM floor heating system with improved heat storage performance in order to reduce the heating energy consumption in the apartment house and predict it performance. The results of the study are as follows.

1) Instead of the existing floor heating system, we propose a PCM floor heating system with excellent heat storage performance and explain its structure and characteristics. 
2) The average surface temperature of PCM floor heating was found to be higher than that of existing floor heating while heating was running again after the heating was stopped.

3) According to the computer simulation, the annual heating energy consumption of the apartment house where the existing and PCM floor heating system is applied is compared, it is confirmed that the apartment house using PCM can save about $2.4 \%$ of the heating energy .

Therefore, compared with existing systems, PCM floor heating system was analyzed to be able to effectively reduce annual heating energy than lightweight foam concrete or mortar due to excellent heat storage performance. It is considered that the comfort of the residents can be improved due to the low temperature change rate of the floor surface temperature.

\section{Acknowledgements}

This research was supported by a grant (18CTAP-C133322-02) from Infrastructure and Transportation Technology Promotion Research Program funded by Ministry of Land, Infrastructure and Transport of Korean government.

\section{References}

[1] S. H. Baek, \& J. C. Park, "Proposal of a PCM Underfloor Heating System Using a Web Construction Method," International Journal of Polymer Science, pp. 1-10, 2017.

[2] S. H. Baek, and J. C. Park, "Performance of Thermal Storage Mass with Phase Change Material in the Under-floor Heating System," Architectural Institute of Korea, vol. 36, no. 2, pp. 509-510, 2016.

[3] S. M. Kim, "Application Technology of Phase Change Heat-storage Building Materials for Climate Change," Architectural Institute of Korea, vol. 61, no. 4, pp. 21-26, 2017.

[4] M. S. Shin, K. N. Rhee, S. R. Ryu, and M. S. Yeo, "Design of radiant floor heating panel in view of floor surface temperatures," Building and Environment, vol. 92, pp. 559-577, 2015

[5] S. Farah, F. Farouk, \& P. H. Biwole, "Phase change materials (PCM) for cooling applications in buildings: A review," Energy and Buildings, vol. 129, pp. 396-431, 2016.

[6] G. Zhou, \& J. He, "Thermal performance of a radiant floor heating system with different heat storage materials and heating pipes," Applied Energy, vol. 138, pp. 648-660, 2015. 